\title{
Dégradabilité in sacco de la matière sèche prélevée par des brebis au pâturage sur parcours steppiques de Crau et sur culture en sec de trèfle souterrain
}

\author{
P Lapeyronie 1, T Adama 2, D Hubert 1, J Gouy 1 \\ IINRA, ENSA-M, Unité de Zootechnie Méditerranéenne, 34060 Montpellier, France; \\ 2School of Agriculture, Fed Univ of Technology, PMB 65 Minna, Nigeria
}

Pour évaluer la dégradabilité dans le rumen du prélèvement végétal moyen réalisé par des brebis au pâturage, des échantillons de "rations simulées" reconstituées à partir de lecture de végétations avant et après pâturage (Hubert, Adama, Lapeyronie, Molénat, 1995, IV Symp Int Nutr Herb), ont été incubés dans le rumen de brebis.

Trois types de couverts végétaux caractérisés par des contributions spécifiques en légumineuses très différentes (PNA : 0 à $2 \%$; PA : 9 à $21 \%$; TS : 41 à $58 \%$ ), ont été pâturés en rotation chacun par un lot de 20 brebis. Les parcelles élémentaires de la rotation étaient d'une superficie permettant l'ingestion de $1500 \mathrm{~g}$ de MS/brebis/j pendant 4 jours. Au sein de chacun des lots, deux brebis fistulées du rumen ont reçu à trois périodes (mi-mars, mi-avril et mi-mai) des sachets d'environ $3 \mathrm{~g}$ de MS (Demarquilly et Chenost, 1969, Ann Zootech, 18, 419-439) contenant des échantillons de rations simulées provenant du même couvert végétal et des sachets d'un foin témoin. Pour chaque durée d'incubation $(6 h, 12 h, 24 h, 48 h, 72 h$ et $96 h) 3$ sachets de foin et 3 sachets de ration ont été utilisés. Le traitement des données (procédure GLM option repeated time, SAS, 1985) est réalisé de façon à analyser l'effet du couvert végétal pâturé et l'effet de la période de mesure sur la cinétique de la dégradabilité.

Les cinétiques de dégradabilité des rations sont très différentes $(P<0.001)$ selon le couvert végétal considéré. Un taux de $78 \%$ est atteint dès $12 \mathrm{~h}$ sur TS mais seulement à $48 \mathrm{~h}$ sur PA et après 72 h sur PNA; II n'est atteint qu'à $96 \mathrm{~h}$ pour le foin dont les valeurs de dégradation sont peu influencées par le milieu d'incubation. Les dégradabilités des rations varient selon la période sur PA et PNA mais pas sur TS.

Les écarts les plus significatifs apparaissent à partir de $12 \mathrm{~h}$ d'incubation $(\mathrm{P}<0.05)$. Ils peuvent être reliés aux végétaux et aux fractions végétales consommés : abondance des légumineuses (PNA vs TS et PA) et contributions du matériel végétal sec ingéré (PNA vs PA). A $96 \mathrm{~h}$, les différences de dégradabilité observées selon les végétations et les périodes diminuent en fonction à la fois de ces mêmes paramètres.

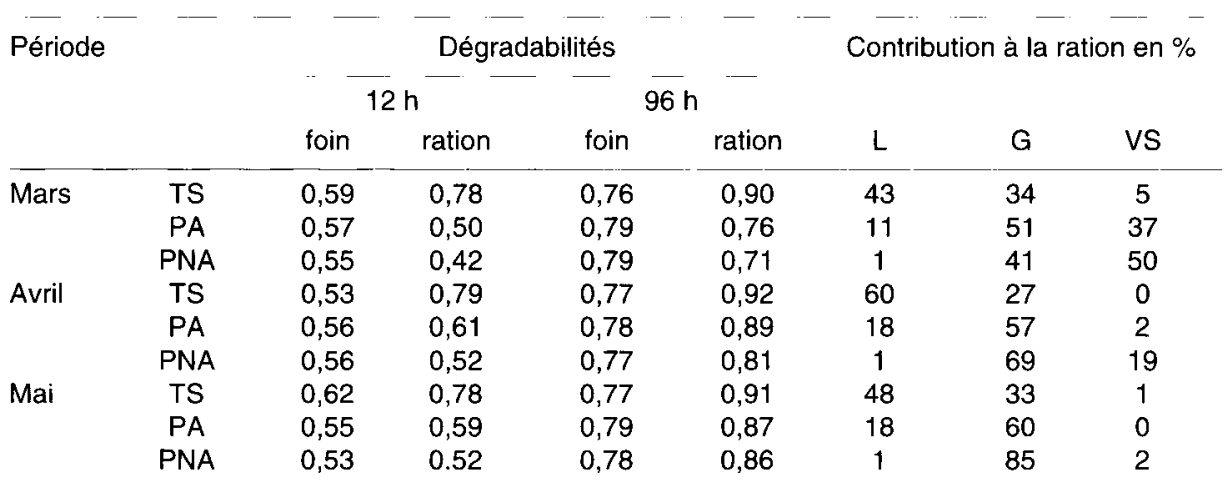

$L$ : légumineuses ; $G$ : graminées ; VS : végétaux secs 